\title{
ENERGY TRANSFER PHENOMENA IN LEAD SULPHATE
}

\author{
G. BLASSE \\ Physical Laboralory, State Uhiversity, Utrecht, The Netherlands
}

Received 22 May 1975

\begin{abstract}
It is shown that lead sulphate, $\mathrm{PbSO}_{4}$, shows $\mathrm{Pb}^{2 \div}$ emission with a Large Stokes shift. Energy transfer has been obsezved from the $\mathrm{Pb}^{2 \div}$ ions to several luminescent centres, viz., tungstate, molybdate, vanadate and rare earths. No transfer occurs to the $\mathrm{Pr}^{3+}$ ion.
\end{abstract}

\section{Introduction}

Recently we have reported on the luminescence properties of vanadate-rare earth associates in $\mathrm{CaSO}_{4}$ and $\mathrm{PbSO}_{4}[1,2]$. In $\mathrm{CaSO}_{4}$ efficient energy transfer from the vanadate group to the trivalent rare earth ions was observed, whereas in $\mathrm{PbSO}_{4}$ this transfer has a much lower probability. This was ascribed to the influence of the $\mathrm{Fb}^{2+} 6 \mathrm{~s}^{2}$ electronic charge distribution on the vanadate group. In this paper we wish to report luminescence phenomena that were observed if excitation occurs into the $\mathrm{Pb}^{2+}$ ions of lead sulphate (and not in the vanadate group as in ref. [2]). It turns out that $\mathrm{PbSO}_{4}$ itself is a luminescent compound and that the presence of several luminescent activators in $\mathrm{PbSO}_{4}$ invoke interesting energy transfer phenomena.

\section{Experimental}

Sample preparation and optical measurements were peiformed as described in refs. [1,2]. Activator concentiations varied from 0.1 to 1 atomic percent.

\section{Results and discussion}

\section{1. $\mathrm{PbSO}_{4}$}

Unactivated $\mathrm{FbSO}_{4}$ shows at room temperature and lower temperatures a broad emission band peaking at about 360 nn if excited with radiation of $\lambda \leqslant 225$ nm. Diffuse reflection spectra show that the optical absorption edge is at about $225 \mathrm{~nm}$ at $300 \mathrm{~K}$. The same emission and excitation bands were found iri $(\mathrm{Ca}, \mathrm{Pb}) \mathrm{SO}_{4}$ and $(\mathrm{Ba}, \mathrm{Pt}) \mathrm{SO}_{4}$ (independent of the lead concentration), so that they are ascribed to intrinsic $\mathrm{Pb}^{2 \div}$ transitions $\left({ }^{1} S_{0}-{ }^{3} P_{1}\right)$ [3]. It is quite unusual that lead compounds show characteristic $\mathrm{Pb}^{2+}$ emission at room temperature, because concentration quenching is very effective [4]. The Stokes shift of this emiscion is very large $(2 \mathrm{eV})$ which prohibits energy transfer among the $\mathrm{Pb}^{2+}$ ions in lead sulphate due to poor spectra] overlap $[5,6]$. The large Stokes shift may possibly be related to the large sites that are available for the $\mathrm{Pb}^{2+}$ ions in the baryte structure, so that a strong contraction upon excitation is possible $[7,8]$. This situation reminds of a number of bismuth compounds ( $\mathrm{Bi}^{3+}$ is isoelectronic with $\mathrm{Pb}^{2+}$ ) where no concentration quenching has been observed due to larga Stokes shifts $\left(\mathrm{Bi}_{4} \mathrm{Si}_{3} \mathrm{O}_{12}[6], \mathrm{Bi}_{4} \mathrm{Ge}_{3} \mathrm{O}_{12}\right.$ [9] and $\left.\mathrm{Di}_{12} \mathrm{GeO}_{12}[10]\right)$.

\section{2. $\mathrm{PbSO}_{4}-\mathrm{Wand} \mathrm{PbSO}_{4}-\mathrm{MO}$}

Tungsten-activated lead sulphate has ceen studied before for excitation into the tungstate group $(\approx 300$ $\mathrm{nm}$ ). A yellow emission was observed and ascribad to a charge-transfer transition between the $\mathrm{Pb}^{2+}$ ions and the tungstate group [11]. This has been confirmed further by van Loo [12]. 


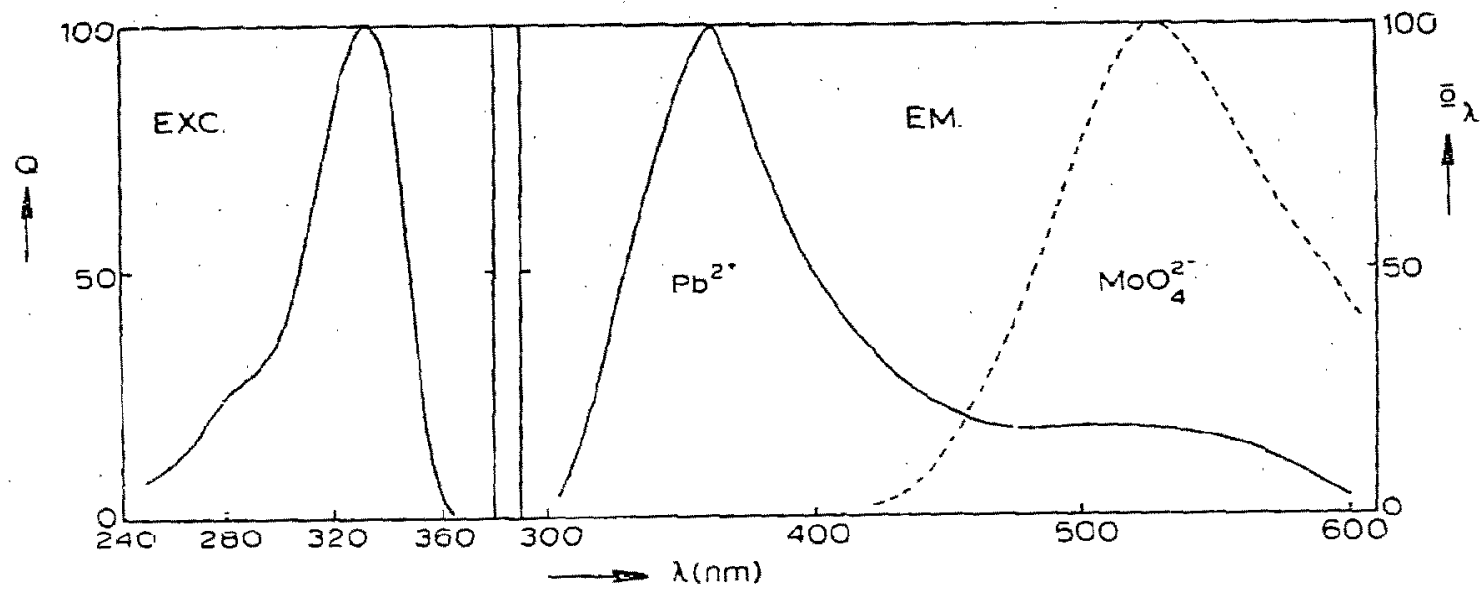

Fig. 1. Relative excitation spectrum of the $510 \mathrm{~nm}$ emission of $\mathrm{PbS}_{0.99} \mathrm{MO}_{0.01} \mathrm{O}_{4}$ at $5 \mathrm{~K}$ (left-hand side; $Q$ gives the relative quantum outpts) and spectrul energy distribution of the emission $3 t 5 \mathrm{~K}$ of this sample (right-hand side; $\Phi_{\lambda}$ gives the spectral radiant power per constant wavelength interval in arbitrary units; drawn line for $225 \mathrm{~nm}$ excitation; broken line for $300 \mathrm{~nm}$ excitation).

In fig. 1 we show the emission and excitation spec. tra of $\mathrm{PbS}_{0.99} \mathrm{Mo}_{0.01} \mathrm{O}_{4}$. Those for the tungsten-activated sampies are very similar. For $225 \mathrm{~nm}$ excitation mainly $\mathrm{Pb}^{2+}$ emission is observed. For $300 \mathrm{~nm}$ ex= citation the molybdate emission appears. The overall transfer from the leac ions to the molybdate group is not very efficient ir the $1 \%$ sample. This is rather surprising in view of the considerable spectral overlap between the $\mathrm{Fo}^{2+}$ emission and the molybdate excitation band (see fig. 1) and must be ascribed to the absence of energy transfer among the $\mathrm{Pb}^{2+}$ ions mu- tually as a consequence of the large Stokes shift. This shows again that the $\mathrm{Pb}^{2+}$ excitation energy is not mobile in this host lattice and further that the $\mathrm{Pb}^{2+}$ ion can transfer its excitation energy to nearest neighbour molybdate (or tungstate) groups.

It is noteworthy that the luminescent spectra of the molybdate and tungstate group are very similar in $\mathrm{PbSO}_{4}$. This is not the case in the alkaline earth molybdates and tungstates [13] or the $\mathrm{Mo}$ - and $\mathrm{W}$-ac. tivated alkaline earth sulphates [14] and can be explained by the assumption that the transitions involved

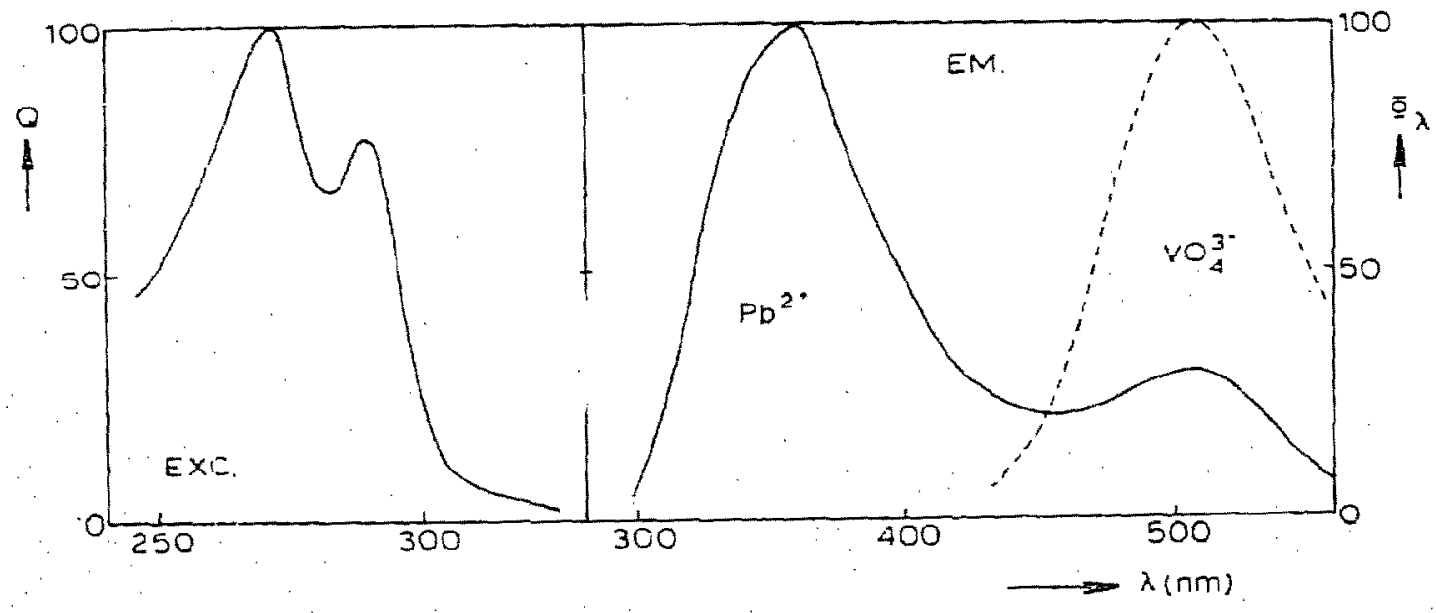

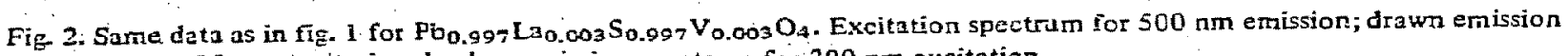
spectrum for $225 \mathrm{~nm}$ excitation, broken emission spectrum for $300 \mathrm{~nm}$ excitation. 
in the lead host latice are of the metal-metal chargetransfer type $[11,12]$.

\section{3. $\mathrm{PbSO}_{4}-V, L n(L n=L a, P r, Y)$}

The compositions show mutually similar luminescent behaviour. For excitation in to the $\mathrm{Pb}^{2+}$ ions $(225 \mathrm{~nm})$ we observe $\mathrm{Pb}^{2+}$ emission (360 nm) as well as vanadate emission $(510 \mathrm{~nm})$ (see fig. 2). This can be interpreted along the same lines as for the molybdate-activation. Energy transfer from the $\mathrm{Pb}^{2+}$ ions to the vanadate group occurs. The spectral overlap is not very large, but the relevant transitions are only slightly forbidden. Usually vanadates, tungstates, etc. are used as host lattices in which activators are introduced. In the present system the situation is reversed which is probably the reason that transfers of this type have not been observed bcfore.

There is no transfer to the $\mathrm{Pr}^{3+}$ ion in $\mathrm{PbSO}_{4}-\mathrm{V}, \mathrm{Pr}$. Transfer from the vanadate group to $\mathrm{Pr}^{3 \div}$ is inefficient as has been shown in ref. [2]. But neither does transfer from the $\mathrm{Pb}^{2+}$ ions to $\mathrm{Pr}^{3+}$ occur. This was also found for the composition $\mathrm{PbSO}_{4}-\mathrm{P}, \mathrm{Pr}$. The phos: phate group has no energy levels in the spectral region concerned. Also in this sample excitation into the $\mathrm{Pb}^{2+}$ ions does not result in $\mathrm{Pr}^{3+}$ emission. There is a simple explanation for this absence of energy transfer, viz., the absence of spectral overlap of the $\mathrm{Pb}^{2+}$ emission and $\mathrm{Pr}^{3+}$ absorption. The energy level scheme of $\mathrm{Pr}^{3+}$ [15] shows a large gap between the ${ }^{3} \mathrm{P}_{2}$ level at $\approx 22500 \mathrm{~cm}^{-1}$ and the ${ }^{1} \mathrm{~S}_{0}$ level at $\approx 48000 \mathrm{~cm}^{-1}$, and the $\mathrm{Pb}^{2+}$ emission of $\mathrm{PbSO}_{4}$ peaks exactly in this gap.

\section{4. $\mathrm{PbSO}_{4}-V, \operatorname{Ln}(\operatorname{Ln}=S m, T b, D y)$}

The results for these compositions are mutually similar, apart from the characteristic $\mathrm{Ln}^{3+}$ enission. We shall, therefore, restrict ourselves to the case of $\mathrm{FoSO}_{4}-\mathrm{V}, \mathrm{Sm}^{3+}$. If a sample of composition $\mathrm{Pb}_{0.997} \mathrm{Sm}_{0.003} \mathrm{~S}_{0.997} \mathrm{~V}_{0.003} \mathrm{O}_{4}$ is excited at $5 \mathrm{~K}$ with $225 \mathrm{~nm}$ excitation, the emission exists for about $70 \%$ of $\mathrm{Po}^{2+}$ emission, $20 \%$ of yanadate emission and $10 \%$ of samarium emission. From our earlier studies [2] we found that excitation into the vanadate group yields about $90 \%$ vanadate emission and only $10 \%$ samarium emission. This means that in $\mathrm{PbSO}_{4}-\mathrm{V}, \mathrm{Sm}$ excitation of the $\mathrm{Pb}^{2+}$ ions at $5 \mathrm{~K}$ is followed by a number of processes indicated in the following scheme:

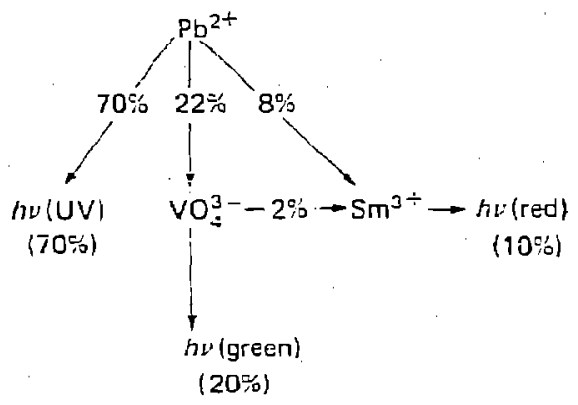

In accordance with this a similar sample with $P$ instead of $\mathrm{V}$ yields $90 \%$ of $\mathrm{Pb}^{2+}$ emission and $10 \%$ of $\mathrm{Sm}^{3+}$ emission (the path way via the vanadate group is no longer available).

It should be realized that the vanadate croup and the $\mathrm{Sm}^{3+}$ ion occur as an associate in $\mathrm{PbSO}_{4}$. We find that the transfer from $\mathrm{Pb}^{2+}$ to the vanadate group is somewhat more efficient than to the $\mathrm{Sm}^{3+}$ ion. It seems hard to account quantitatively for this effect. Nevertheless this result indicates that, comparing $\mathrm{Pb}^{2+} \rightarrow \mathrm{VO}_{4}^{3-}$ and $\mathrm{Pb}^{2+} \rightarrow \mathrm{Sm}^{3+}$ transfer, the smaller spectral overlap in the case of $\mathrm{Po}^{2+}-\mathrm{VO}_{4}^{3-}$ transfer is more than compensated by the stronger interaction (electric dipole-dipole); in the case of $\mathrm{Pb}^{2+}-\mathrm{Sm}^{3+}$ transfer the $\mathrm{Pb}^{2+}$ emission overiaps favourably with many $\mathrm{Sm}^{3 \div}$ absorptions, but the interaction is either of the electric dipole-quadrapole or of the exchange type in view of the forbidden nature of the $\mathrm{Sm}^{3 \div}$ transitions [16].

\section{Acknowiedgement}

The author is indebted to Mr. G.P.M. van den Heuvel for the preparation of the samples and the performance of the measurements.

\section{References}

[1] W.T. Draai and G. Blasse; Phys. Stat. Soi. 21 a (1974) 569; Chem. Phys. Eetters 25 (1974) 167.

[2] G. Blasse and G.P.M. van den Heuvel, J. Luminescence (1975), to be published.

[3] F. Seitz, J. Chem. Rhys. 6 (1938) 150. 
[4] H.A. Klasens, A.F. Floekstra and A.P.M. Cox, J. Electrochem. Soc. 104 (1.957) 93;

W.C. de Giuyter ancl T. Bokx, J. Solid State Cñem. 6 (1973) 271.

[5] D.L. Dexter and J.H. Schuiman, J. Chem. Phys. 22 (1954) 1063 .

[6] G. Rlasse, Fhilips Rei. Rept. 23 (1968) 344.

[7] D.L. Dexter, Solid State Phys. 6 (1968) 353.

[8] G. Blasse, J. Chem. Fhys. 51 (1969) 3529.

[9] M.I. Weber and R.R. Monchamp, J. Appl. Phys. 44 (1973) 5495 .
[10] R.B. Lauer, Appl. Phys. Ietters 17 (1970) 178.

[11] G. Blassc and A. Bril, Philips Res. Rept. 24 (1969) 275.

[12]. W. van Loo, Phys. Stat. Sol. 27a (1975) 565; 28a (1975) 227.

[13] F.A. Kuöger, Some aspects of the luminescence of solids (Elsevier, Amsterdam, 1948).

[14] Y. Kotera, M. Yonemura and T. Sekine, J. Electrochem. Soc. 108 (1961) 540.

[15] G.H. Dieke, Spectra and energy levels of rare earth ions in crysta!s (Interscience, New York, 1968).

[16] D.L. Dexter, J. Chem. Phy's. 21 (1953) 836. 